\title{
Effects of a 6 Brick Duplo Block guided play intervention on pre-literate learners' visual perception
}

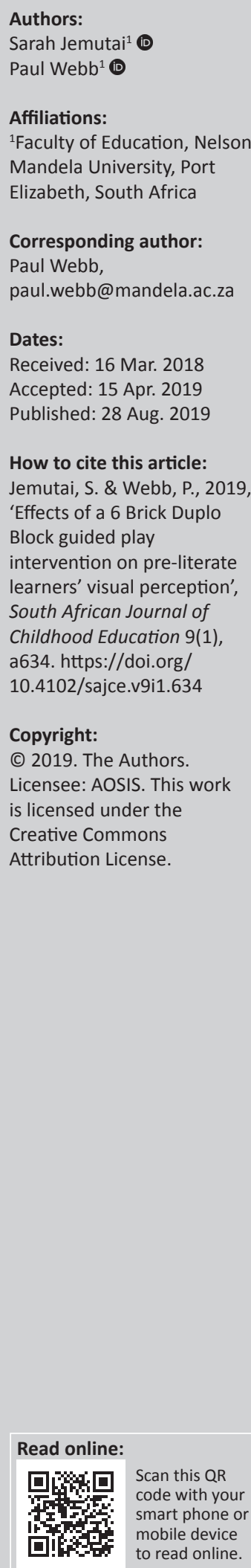

Background: Literature reveals that guided play promotes the development of visuospatial abilities essential for learning to read, write and do mathematics. However, most of these findings have focused on older children who are already literate, and the tests and the instruments used were designed for children in Western contexts.

Aim: As there is little data on the development of visuospatial abilities in pre-literate children in African contexts, this study set out to explore the effects of using a guided block play intervention on the development of these abilities in pre-literate children.

Setting: The study was carried out in two classrooms (one experimental and the other comparative) in each of two schools, one in South Africa and one in Kenya.

Methods: The study used a pre- and post-test, quasi-experimental, mixed-methods approach. The intervention and test used, namely, the Visual Perception Aspects Test, were designed and validated in African contexts.

Results: The data revealed that using the 6 Brick Duplo Block guided play approach statistically significantly accelerated the development of visuospatial abilities in pre-literate children in the experimental groups over those in the control groups (no intervention). The data also revealed that the greatest improvements were made among children who had few prior opportunities to engage in guided play using physical manipulatives.

Conclusion: The overall findings of the study suggest that the development of aspects of visuospatial perception is accelerated when teachers use this approach to facilitate guided play. This finding has implications for promoting the development of reading, writing and numeracy skills in pre-literate children.

Keywords: guided play; visuospatial perception; 6 Brick Duplo Blocks; Visual Perception Aspects Test; VPAT; accelerated visuospatial development.

\section{Introduction}

A crucial aspect of child development is the development of perceptual skills during the early learning years. Visuospatial perception, which plays a fundamental role in determining a young learner's ability to successfully complete written and numeric tasks (Clutten 2009), is the brain's ability to organise and interpret what is seen (Deiner 2005). Visuospatial perception brings meaning to what the eyes see and plays a fundamental role in a learner's ability to learn, read and spell; in other words, it facilitates the accomplishment of written and numeric tasks vital for academic competence (Scheiman \& Gallaway 2006; Schieman \& Rouse 2006).

Children, whether playing informally or functioning within an academic environment, have a tendency to learn through the regular use of their eyes (Atherton \& Gates 2007; Gentile 2005). Only 20\%-30\% of learners learn more effectively through the auditory channel compared with at least $40 \%$ who learn more effectively when presented with visual information (Schneck 2005). One of the ways of acquiring visuospatial abilities is through play where the primary learning channel is vision (Sattler \& Evans 2002). Although a great deal of research has been done on play internationally (Whitebread \& O'Sullivan 2012), play has not been taken particularly seriously in African settings (Ogunyemi \& Ragpot 2015). The few research studies on play and visuospatial perception that have been done in Africa have been done mainly in South Africa with literate children but little to nothing has been done with children in the crucial early learning years before formal schooling (Brey 2017). These observations underpin the exploratory research that was undertaken and described in this article. 


\section{Children and play}

Play is a child's 'work' that helps thinking, doing and feelings to flourish (Hewes 2006). It is an activity where everything becomes possible and freedom of imagination takes precedence (Elkonin 2005). It is an instinctive, flexible, malleable, natural and creative process that instinctively leads to a well-developed imagination (Tsao 2008; Wardle 2006). Through play children get the opportunity to assimilate reality into their experience and hence make it part of their own lives (Elkonin 2005). Play develops in children in a predictable pattern, which is linked to their intellectual, emotional, social and physical aspects of development (Bennett 1997; Kalliala 2005; Whitebread \& O'Sullivan 2012).

Piaget, Montessori and Vygotsky agree on the important relationship between play and cognitive development (Mielonen \& Paterson 2009). Piaget (1964) notes that understanding children's stages of development is important if one is to facilitate play that helps them to fully realise the potential of their physical and mental capabilities. Teachers and adults, who often help define the boundaries of their children's play, need to know the developmental stage that the children are at if they are to transform random play into activities that are vital for their development (Edwards 2000; Piaget 1962). Vygotsky agrees that play has an important role in facilitating cognitive development in that children not only put into practice what they know, but in the process of play they get to learn new things from each other and from their surroundings (Mielonen \& Paterson 2009). Piaget also asserts that young children develop meaning through interacting with their environment, particularly in his preand concrete operational cognitive development stages (Mielonen \& Paterson 2009). At these stages children develop the ability to retrace their thinking through a phenomenon he termed as 'reversibility' (Mooney 2000:78). Through reversibility children develop the ability to solve higher scale problems and to begin thinking abstractly (Mooney 2000). Such notions place play as a strategic niche in children's cognitive development.

One form of play is guided block play. Blocks have been used by children for playing for centuries. John Locke introduced alphabet blocks as early as 1693 (Hewitt 2001). In the mid1900s, Pratt (1948) introduced unit blocks, which have been used uninterruptedly in the United States to teach mathematics to date. In the early 1900s, Maria Montessori noted the importance of block building in terms of cognitive and intellectual achievement (Whitebread \& O'Sullivan 2012). Montessori, whose theories have influenced the way many Early Childhood Development programmes are structured (Mooney 2000), emphasises that children develop literacy skills through play. In turn, literacy skills are dependent visuospatial abilities (Scheiman \& Gallaway 2006; Schieman \& Rouse 2006).

While mechanisms to develop children's visuospatial abilities have not yet been clearly defined, it is known that when children play they develop important basic brain functions
(Nath \& Szücs 2014). One such function is visuospatial ability. As there is little data on the development of visuospatial abilities in pre-literate children in African contexts, this study set out to explore the effects of using a guided block play intervention on the development of the three basic visuospatial abilities, namely, visual discrimination (VD), visual memory (VM) and visual sequential memory (VSM), all of which are essential aspects for enhancing literacy and mathematical capabilities (Clutten 2009).

\section{Research design and methods}

In the following section, the study design is outlined, the setting and sample is described, the intervention explained, the data collection and analysis discussed and ethical issues around the study explained.

\section{Design}

This study utilised a quasi-experimental design with preand post-testing of experimental and comparison groups. The design is quasi-experimental and not truly experimental as the experimental and comparison groupings were not randomly chosen (existing classes were used) and the numbers were relatively small. Quantitative data were generated via pre- and post-tests of the participating children in the three aspects of visuospatial perception, namely, VD, VM and VSM. Grade R children (5-7 years old) in one South African and one Kenyan school were chosen to serve as both purposive and convenience samples. Sampling was purposive in that the two schools that were chosen are both broadly representative of urban Grade $\mathrm{R}$ classes in South Africa and Kenya. The fact that the schools chosen are in South Africa and Kenya was not to make comparisons in terms of countries, but was a convenient way of sampling. The convenience aspect came about as the first author studied in South Africa, but, after doing the initial fieldwork in South Africa, went back to Kenya. However, after purposively identifying a conveniently situated school in Kenya that was similar in terms of socio-economic grouping, class and school size, language and so on, it became apparent that the school in Kenya was different in one aspect, mainly that there was a dearth of play resources in the Kenyan school. This difference was taken into account as a variable when considering the results of the research.

As noted, there were two Grade R classes in each of the South African and Kenyan schools chosen. In Kenya this level of schooling is not called 'Grade R', but is equivalent to Grade $\mathrm{R}$ in South Africa. One class in each school constituted the experimental group and their teacher received 'treatment' (an intervention based on guided play using the 6 Brick Duplo Block approach), while the other provided a comparison group that had not received the 'treatment'. The teachers in each school decided who would be the 'experimental' teacher and who would be the 'comparison' teacher on the understanding that enough material (Duplo blocks and teachers' guide files) would be supplied by the researchers and that the 'comparison' teacher would have 
equal access to support from the researchers once the experimental stage of the intervention process (training of 'experimental' teachers, pre- and post-testing of the children and the teaching intervention over 6 months) was complete.

The intervention included providing the experimental group teachers with training and sufficient sets of 6 Brick Duplo Blocks to allow all of the children in their classes to participate in the pre-designed Duplo Blocks activities individually over 6 months. The 6 Brick Duplo Block activities that were identified and selected by the researchers as having the potential to promote VD, VM and VSM were used for the intervention.

In order for the researchers to be able to confirm that the intervention took place as planned, the teachers filled in a record sheet each time they engaged their learner with 6 Brick activities. The information on the record included the date, activity name, number of bricks used, whether the learners completed the activities or not, whether the teacher felt that the children had understood the activity (fully, partially or not at all) and whether they had enjoyed it (fivepoint Likert scale). There was also space for any additional comment that the teacher might like to make. Classroom observations were made concerning how the teachers and learners engaged in the activities (a minimum of five visits per experimental class) and the teachers were interviewed individually on completion of the intervention and testing phase of the study in their schools in South Africa and Kenya.

The VD, VM and VSM abilities of the children in both the experimental and comparison classes were tested using the Visual Perception Aspects Test (VPAT) immediately prior to the intervention. The same test was used as a post-test immediately after the intervention. As the psychological test is carried out on a one-on-one basis with the tester guiding the pre-literate children through the process, five final-year psychology students at the university were recruited on a voluntary basis to carry out the visuospatial abilities testing in the South African school where the study was conducted. Guidance in terms of their selection was provided by a professor in the Psychology Department at the university and, after final selection, they were made conversant with the VPAT testing procedures. These processes were repeated in Kenya with final-year psychology students and a psychology professor from another university.

\section{Sample and setting}

As noted above, two classes of pre-school children in two schools (one school in South Africa having a comparison and experimental class and the other school in Kenya also with comparison and experimental classes) participated in the study. This empirical investigation's sampling frame focused on government schools of almost similar size and representing an urban population where second-language learners are taught in English (a reasonably common situation in both countries). The schools were also chosen because of links with teachers who were part of previous research studies and who had prepared to be part of the process. The participating children ranged between the ages of 5-7 years. This age group was chosen because research suggests that, taking into account verbal and non-verbal intelligence, visuospatial ability may be a unique underlying mechanism which can be used to account for differences in higher order academic performance at this age (Mayer et al. 2014). The sample size was approximately 80 learners, that is, 40 learners from each school with approximately 20 children in each class.

\section{Research intervention}

Permission was granted by the Care for Education and Hands on Technologies group to choose and implement ' 6 Bricks' activities from the resources they provide. After personally carrying out the over 100 activities available, 30 were chosen as activities that required and were suitable for developing the skills of VD, VM and VSM.

After choosing the activities from the Care for Education and Hands on Technologies booklet, they were photocopied in colour and put in the same order in five different files, one each for the four teachers and one for the researcher. The files contained activities on the different aspects in the order VD, VM and VSM, record of completed activities, completed record sheets containing the date, activity name, number of blocks used, whether the learners completed the activity, learners' enjoyment of the activity and a section was left blank for comments. The comparison group teachers only received their files, blocks and training once the intervention period and data generation were completed.

The training of the experimental teachers was done by the researchers over two half-day sessions. Workshops were conducted individually with the two experimental teachers to develop their understanding of the ' 6 Bricks' approach and how to implement it in their classes. During these workshops they experienced first-hand some of the activities they would conduct with their learners and how they should complete a 'teacher record sheet' after each activity. After the workshops, the teachers were provided with enough sets of ' 6 Bricks' for each of their learners to have their own set of ' 6 Bricks', a file containing the ' 6 Bricks' play activities that they were expected to cover over the duration of the intervention, and pages of teacher record sheets to be filled in after each activity. Not only were the teachers trained and guided in terms of how play should be facilitated when using the 6 Bricks approach, they were also given insight about the possible relationships between guided play and the development of visuospatial perception.

The experimental and comparison teacher (the ones who did not receive training or the 6 Brick Duplo Blocks) in each school worked independently from one another. The children in the experimental classes each received a set of 6 Brick Duplo Blocks, one of each colour, which they kept on their desk readily available throughout each school day so that the teachers could easily facilitate play at any given time that they felt was appropriate. The children's visuospatial abilities 
were pre- and post-tested before and after the experimental group teachers implemented the intervention with their learners. The pre- and post-tests used were the first three sections of the VPAT. These sections dealt with the visuospatial perception aspects of VD, VM and VSM.

The teachers facilitated the 6 Brick activities as set out in their files. Four 10-min activities were to be carried out separately on 4 days of each week. The order of the activities each week was an activity that aimed at developing VD, followed on consecutive days by activities that aimed at promoting VM and VSM, respectively. The fourth day of the week was reserved for teachers to repeat any activity that they believed was not well understood by the children. The approach was for the teacher to demonstrate an activity (building a shape, sequencing different coloured blocks, etc.) and then asking their learners to replicate what they had done before continuing to play (building their own shapes, sequencing their own colours, etc.).

Open-ended classroom observations were done by the researcher in the course of the intervention period to observe how the teachers facilitated guided play and how they maintained their guided play records in the files. The experimental group teachers were interviewed individually after the intervention and the classroom observation field notes were interrogated to help explain the quantitative data findings. These teacher interviews, conducted after the posttests, were audio and video recorded.

\section{Data generation}

The Visual Perception Aspects Test, developed by Sylvia Clutten in South Africa in 2009, was used to measure visuospatial skills in this study. The validity and reliability of this test was the core of Clutten's research and, as it was shown to be both reliable and valid in the South African context, no measures of validity or reliability were deemed necessary. Clutten (2009) identified nine aspects of visual perception, the development of which she considers essential for the effective processing of visual information and learning, as well as the academic performance and competency of learners. These nine visual perceptual aspects are as follows: VD, visual form constancy, VM, VSM, visualspatial relationships, position-in-space, visual closure, visual figure-ground, and visual analysis and synthesis. Only three of these visuospatial perception aspects were considered in this study.

Each subtest, namely, a test of one of the aspects of visuospatial perception, comprises 16 items that are made up of shapes, forms or designs arranged from easy to more complex forms. Each initial form is presented in a stand-alone box. The child is instructed to observe the form and then instructed to choose an answer from a multiple-choice selection of forms or designs. Every successful response is awarded one mark and the marks are added to provide a total raw score for that specific subtest. If the respondent answers three consecutive questions unsuccessfully, the tester moves on to the next

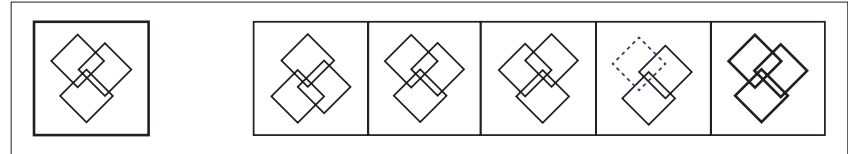

Source: Clutten, S.C., 2009, 'The development of a visual perception test for learners in the foundation phase', Unpublished Master's Dissertation, University of South Africa, Pretoria. FIGURE 1: Example of an item from the visual discrimination subtest of the visual perceptual aspects test.

subtest. An example of a question in the test, namely, one on VD, is illustrated in Figure 1. There were also visual perceptual aspect tests that used toy shapes (squares, triangles, stars, etc.), which had to be identified in 2D (2-dimentional) on paper.

Each test was administered as a pencil-and-paper test under the individual guidance of the psychology students and the researchers. This process took approximately 20-30 minutes per child tested. As at least five children could be tested at a time by the five testers and the researcher, the entire group per school (experimental and control) could be tested during the course of one school day during class time. Testing took place in a nearby room, which was provided for the purpose by the schools. These rooms had a sufficient number of small tables and chairs to enable testing in an environment that was not crowded. The children were drawn from their classrooms in batches of five or six, depending on the number of testers available, and escorted to and from the testing venue.

Pencils were provided to mark the selected shape and patterns on the test paper. The children put a mark on the selected answer on the test booklet and the researcher and the psychology students recorded the children's answers selected on a separate answer sheet each time during the testing session (pre- and post-test). This 'double recording' was done to try to keep to a minimum any ambiguities that may have occurred in the children's responses on their test sheets. The testers answer sheets and the children's test booklets were inspected to check for errors and omissions. These data were recorded in a spreadsheet according to the three aspects of visuospatial perception on which the study focused, namely, VD, VM and VSM, and the variables provided by the biographical data obtained on the test booklets. The biographical data were filled in by the teacher and included variables such as an identifying number (to enable matched pairs, pre- and post-testing), gender, age, whether the children wore glasses or not, experimental or control group, pre- or post-test, and country. A codebook using numbers was recorded in the spreadsheet to explain the recorded results per code to enable statistical analysis.

After pre-testing, the two schools then followed a 4-month intervention period during which the experimental class teacher guided the children to play with the 6 Bricks. Openended observations were made during visits to the schools. Open-ended observations and field notes were taken on at least five occasions in the experimental group classes during the intervention period when the experimental teachers gave advance warning that they were going to implement the 
strategy at a specific time. After the post-testing exercise was completed by both the experimental and comparison groups of children, semi-structured interviews were held with the experimental group teachers. The interventions in South Africa and Kenya could not be done simultaneously, and therefore they overlapped to a degree to allow travel arrangements. The South African group started and ended the intervention earlier than the Kenyan group, but the testing and interventions in both countries were completed between the months of May and October in 2016.

\section{Data analysis}

The quantitative data from the VPAT testing was subjected to statistical analysis to generate descriptive statistics such as sums (totals), counts, averages (means) and standard deviations. Even though the sample was small $(n=77)$, the data were distributed sufficiently to use parametric statistics. As the data generated were matched pairs, and because $t$-tests are least subjected to the effects of small data sets (Carlberg 2011), this test was chosen to investigate whether there were any statistically significant differences between group scores and between changes in mean scores in the groups of children tested. As the samples were relatively small, a $90 \%$ level of confidence $(p \leq 0.1)$ was selected as the indicator of significant difference between groups. This level of confidence is considered to be very low in statistical terms but has been used by some social scientists in the past depending on the nature of their study and was considered to be appropriate for this small scale, master's degree level, study (Carlberg 2011). Where higher levels of confidence were attained, these were considered to be bonus findings.

\section{Ethical considerations}

Prior to data collection, the schools in South Africa and Kenya were visited to discuss the aims, research design and methodology of the study with the school principals and Grade $\mathrm{R}$ teachers. The teachers volunteered to take part in the study and were assured that their responses would only be used for the purposes of this research. The teachers who participated in the intervention and the semi-structured interviews signed written consent forms, as did the parents of the Grade R learners from the two schools. The participants' anonymity was kept throughout the study.

Ethics approval of this particular study was provided by the Faculty of Education Research, Technology and Innovation Ethics Committee and the Human Ethics Committee at the Nelson Mandela University as an addendum to an umbrella study conducted under ethics number H14-EDU-ERE-014.

\section{Results}

Quantitative data were obtained from the VPAT results of 77 pre-school children from two Grade R classes in a school in the Republic of South Africa (RSA) $(n=38)$ and two classes of pre-school learners $(n=39)$ from a school considered to be acceptably equivalent in Kenya. One class in each school served as an experimental group and the other as a comparison group. In each case only matched pairs of prepost data were used. In other words, only the data generated by children who completed both the pre- and post-tests were used. The number of matched pair children in each class in South Africa and Kenya is presented in Table 1.

As the data were normally distributed and generated as matched pairs, and because $t$ tests are least subject to the effects of small data sets even if the data are not distributed normally (Carlberg 2011), this test was chosen to investigate whether the apparent differences suggested by the descriptive statistics were statistically significant. This choice was supported further by the fact that the standard deviations $(\sigma)$ of each group were not dissimilar (Table 2).

A comparison of the pre- and post-test mean scores revealed that there were statistically significant differences between the South African and Kenyan scores with the South African groups achieving, statistically, significantly better in both cases. Application of a $t$ test to the data revealed that the pretest mean scores of the children in the Kenyan schools were lower at a statistically significant difference at the $99 \%$ level of confidence. However, the level of confidence at which this statement can be made dropped from the 99\% level of confidence $(p \leq 0.01)$ in terms of the pre-test data to the $95 \%$ level of confidence $(p \leq 0.05)$ for the post-test data (Table 3$)$.

All of the groups (experimental and comparison groups in both schools) mean scores improved from pre- to post-testing with both the South African groups attaining higher scores on their VPAT pre-test scores than the Kenyan groups posttest scores. A closer look at the change in mean score's reveals that the greatest changes in mean scores took place in the

TABLE 1: Number of participants in the South African and Kenyan schools' experimental and comparison groups.

\begin{tabular}{lccc}
\hline Country & Experimental & Comparison & Total \\
\hline South Africa & 18 & 20 & 38 \\
Kenya & 19 & 20 & 39 \\
\hline Total & $\mathbf{3 7}$ & $\mathbf{4 0}$ & $\mathbf{7 7}$ \\
\hline
\end{tabular}

South Africa, $n=38$; Kenya, $n=39$

TABLE 2: South African and Kenyan pre-test number of participants, mean scores and standard deviations.

\begin{tabular}{lcccc}
\hline Pre-test & $\begin{array}{c}\text { RSA } \\
\text { comparison }\end{array}$ & $\begin{array}{c}\text { RSA } \\
\text { experimental }\end{array}$ & $\begin{array}{c}\text { Kenya } \\
\text { comparison }\end{array}$ & $\begin{array}{c}\text { Kenya } \\
\text { experimental }\end{array}$ \\
\hline $\boldsymbol{N}$ & $\mathbf{2 0}$ & $\mathbf{1 8}$ & $\mathbf{1 9}$ & $\mathbf{2 0}$ \\
\hline Mean score & 25.35 & 28.06 & 18.05 & 19.42 \\
$\sigma$ & 5.16 & 7.62 & 6.86 & 6.01 \\
\hline
\end{tabular}

RSA, Republic of South Africa; $N$, number; $\sigma$, standard deviations.

TABLE 3: Comparison of the Kenyan and South African groups mean scores in the Visual Perception Aspects Test pre- and post-tests with $t$ test probability value $(p)$.

\begin{tabular}{|c|c|c|c|c|c|c|c|}
\hline \multirow[t]{2}{*}{ Test } & \multicolumn{3}{|c|}{ Kenya } & \multicolumn{3}{|c|}{ South Africa } & \multirow[t]{2}{*}{$p$-value } \\
\hline & $n$ & Mean & $\sigma$ & $n$ & Mean & $\sigma$ & \\
\hline Pre & 39 & 18.8 & 6.3969 & 38 & 26.6 & 6.5033 & $p \leq 0.01 *$ \\
\hline Post & 39 & 23.9 & 6.2386 & 38 & 29.4 & 5.0172 & $p \leq 0.05 * *$ \\
\hline
\end{tabular}

$n$, number; $\sigma$, standard deviations.

*, Statistically significant at the $99 \%$ level of confidence.

$* *$, Statistically significant at the $95 \%$ level of confidence. 
experimental groups both in South Africa and Kenya, namely, changes of 3.78 and 6.68, respectively (Figure 2). It is, however, interesting to note that the change in mean score in the Kenyan comparison group was almost as large as the change in mean score in the South African experimental group (Figure 2) and, as noted earlier, the level of confidence dropped from the $99 \%$ level of confidence $(p \leq 0.01)$ in terms of the differences in the pre-test data to the $95 \%$ level of confidence $(p \leq 0.05)$ for the post-test data (Table 3).

The gains in mean scores in terms of visuospatial perception in the comparison groups are not unexpected as at this age there is normally growth in terms of this ability (Tsai, Wilson $\& W u$ 2008). The question is whether there is any real difference between the changes in the pre- and post-test mean scores $(\delta x)$ and between the experimental and control groups in Kenya and South Africa. This question can be answered using inferential statistics that include $t$ tests for statistical significance and Cohen's $d$ as an indicator of practical significance (Table 4 ).

As noted earlier, the samples were relatively small and therefore a $90 \%$ level of confidence ( $p \leq 0.1$ ) was selected as the indicator of significant difference between groups. While, as noted above, this level of confidence is generally considered to be low in statistical terms (Carlberg 2011), it has been used by social scientists depending on the nature of their research, and was considered to be appropriate for this study. Using this indicator of confidence, the inferential statistics reveal that there is a difference between the change in mean scores of the Kenyan experimental and control groups, while in the South African school, although the change appeared large

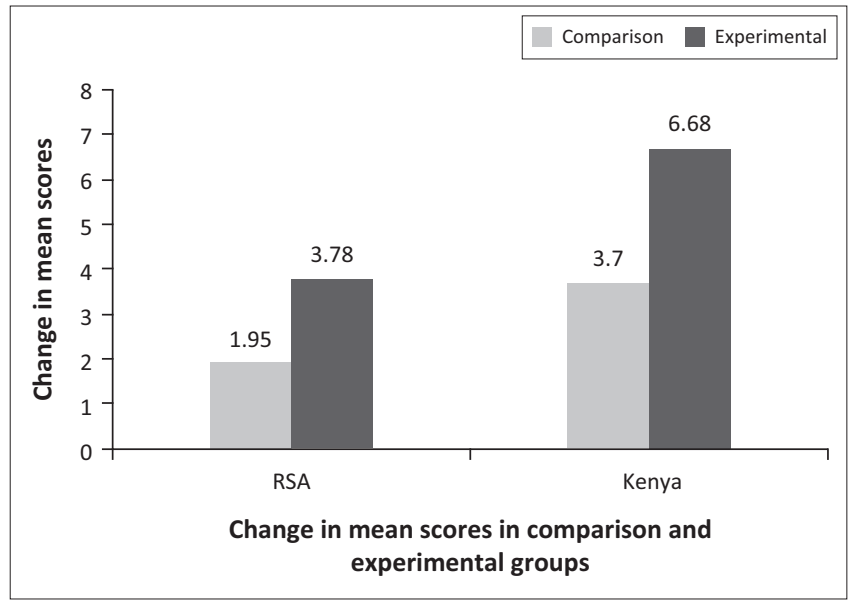

FIGURE 2: Change in mean scores in the comparison and experimental groups in the South African and Kenyan groups.

TABLE 4: Comparison of mean score changes between the experimental and control groups in Kenya and South Africa.

\begin{tabular}{|c|c|c|c|c|c|c|c|c|}
\hline \multirow[t]{2}{*}{ Country } & \multicolumn{3}{|c|}{ Control } & \multicolumn{3}{|c|}{ Experimental } & \multirow[t]{2}{*}{$p$} & \multirow[t]{2}{*}{ Cohen's d } \\
\hline & $n$ & $\delta x$ & $\sigma$ & $N$ & $\delta x$ & $\sigma$ & & \\
\hline Kenya & 20 & 3.7 & 6.913 & 19 & 6.68 & 6.790 & $0.0911 * * *$ & 0.2 \\
\hline RSA & 20 & 1.95 & 5.558 & 18 & 3.78 & 6.025 & 0.1685 & $\mathrm{~N} / \mathrm{A}$ \\
\hline
\end{tabular}

RSA, Republic of South Africa; N/A, not applicable; $n$, number; $\delta x$, mean scores, $\sigma$, standard deviations; $p$, $p$-value.

$* * *$, Statistically significant at the $90 \%$ level of confidence. (see Figure 2), there is no statistically significant difference between the changes in mean score in the experimental and control groups (Table 4).

Classroom observations revealed that the teachers were able to implement the 6 Brick strategy as required and that the children participated actively and with enthusiasm. The teacher record sheet revealed that both experimental class teachers had completed most of the activities expected of them. The semi-structured interviews revealed that the teachers had enjoyed facilitating the activities and that their learners had participated actively. The teachers noted that the children had enjoyed the intervention and that they believed that the activities had improved their visuospatial abilities (this observation is highly subjective, but supported the quantitative findings). The qualitative data also supported the quantitative findings that the children who had previously had little to no manipulatives and guided playtime at school responded most positively to the intervention.

\section{Discussion}

The quantitative data generated in this study suggest that use of the 6 Bricks Duplo Block strategy does accelerate the development of pre-literate learners' VD, VM and VSM abilities. These findings are in accordance with Piaget's theory of child development, which involves changes in cognitive process and abilities. Such changes are not attained passively, but through actively playing a role in learning about the world around them (Piaget 1953). During Piaget's preoperational stage children aged 2-7 years old begin to think symbolically and learn to use words and pictures to represent objects. During this stage they begin to use symbols, which are dependent on visuospatial perception. The children who took part in this study were in Piaget's preoperational stage of development (ages 2-7), a stage where play is closely linked to cognitive and intellectual achievement (Piaget 1962; Whitebread \& O'Sullivan 2012).

The claim, that the use of block play in the manner that it was carried out in this study accelerates the development of preliterate learners' VD, VM and VSM abilities, is sustained by the accompanying qualitative data which revealed that the teachers were able to implement the strategy successfully, the children exhibited a high level of engagement and enjoyed the activities, and that the teacher's perceptions that their learners' visuospatial abilities improved after engaging in the intervention. This link is warranted within theoretical notions of the development of visuospatial skills, and backed by findings of similar work with young literate children (Brey 2017). It is also backed by Piaget's conception that the external construction of physical artefacts is a powerful means to achieve an internal construction of understanding through the effect of play.

Both the quantitative and qualitative data generated suggest that the strategy was most effective in classes where the teachers had previously provided their children with little to no guided play and had little access to play materials. As 
noted earlier, the Kenyan school data indicated a greater improvement compared to the data generated in the South African school, namely, there was a higher mean score increase in the Kenyan classes than in the South African ones. Comparing the two schools during the open-ended classroom observation, it was clear that the availability of play resources was inadequate in the Kenyan school. As such, it can be inferred that the provision of sets of 6 Bricks in their classes was a factor in terms of an improvement in visuospatial perception after the intervention. This statement resonates with Kellman and Arterbery's (2006) belief that play is accompanied by the development of routine visual functions, which enables learners to carry out their daily life activities, hence the proposition that the daily routine of a child should be one in which the child is surrounded by a multitude of visual stimuli, preferably those that presented dynamically and result in active engagement, as was the case with the guided block play approach used in this study.

As teachers and adults are often required to help define the boundaries of their children's play, it is important that they know the developmental stage that the children are at if they are to transform random play into activities at an early age to help the development of cognitive abilities (Edwards 2000; Mielonen \& Paterson 2009; Piaget 1962; Vygotsky 1978). In terms of pre-literate and newly literate young children, this is the preoperational stage where they begin to engage in symbolic play and learn to manipulate symbols. At this stage children are able to retrace their thinking through reversibility, which enables them to develop the ability to begin thinking abstractly (Mooney 2000). To think abstractly, children need to have developed the appropriate level of visuospatial ability as opposed to mere sensory association (Kellman \& Arterberry 2006).

The claim that guided play using the block play approach used in this study accelerates the development of three basic visuospatial abilities in pre-literate children is important as the development of these visuospatial skills are integral in the acquisition of literacy and numeracy skills (Clutten 2009). As such, the findings of this study, though limited in scope and range, should make a contribution to the understanding of the means to, and necessity of, advancing visuospatial skills in preparation for the development of literacy and numeracy in young children. It also provides evidence that these skills can be measured in pre-literate children using a test that was developed and validated for African conditions, namely, the VPAT.

\section{Acknowledgements}

The authors also acknowledge the assistance given by Amina Brey in terms of assistance in the field at schools and her unofficial supervision support.

\section{Competing interests}

The authors declare that they have no financial or personal relationships that may have inappropriately influenced them in writing this article.

\section{Authors' contributions}

The contents of this article are the findings of S.J.'s MEd. P.W. conceptualised the study, was the academic supervisor and assisted in writing the article.

\section{Funding information}

S.J. was supported financially and academically as a German Academic Exchange Service (DAAD) scholarship holder and member of the East and South African German Centre of Excellence in Educational Research and Research Management (CERMESA).

\section{Data availability statement}

The authors have numerical data that are new and were analysed and they are happy to share the data if asked.

\section{Disclaimer}

The views and opinions expressed in this article are those of the authors and do not necessarily reflect the official policy or position of any affiliated agency of the authors.

\section{References}

Atherton, H. \& Gates, B., 2007, A history of learning disabilities, Churchill Livingstone, Edinburgh.

Bennett, N., 1997, Teaching through play: Teachers' thinking and classroom practice, Open University Press, Buckingham.

Brey, A., 2017, 'The effect of "6 Bricks" guided play on grade two learners' visual perception and reasoning abilities', Unpublished Doctoral Dissertation, Nelson Mandela Metropolitan University, Port Elizabeth, South Africa.

Carlberg, C., 2011, Statistical analysis: Microsoft 2010, Pearson Education, New York.

Clutten, S.C., 2009, 'The development of a visual perception test for learners in the foundation phase', Unpublished Master's Dissertation, University of South Africa, Pretoria.

Deiner, P.L., 2005, Resources for educating children with diverse abilities: Birth through eight, 4th edn., Thomson/Delmar Learning, Clifton Park, New York.

Edwards, C.P., 2000, 'Children's play in cross-cultural perspective: A new look at the six cultures study', Cross-Cultural Research 34(4), 318-338. https://doi.org/10. $1177 / 106939710003400402$

Elkonin, D.B., 2005, 'Chapter 3: Theories of play', Journal of Russian \& East European Psychology 43(2), 3-89. https://doi.org/10.1080/10610405.2005.11059246

Gentile, M., 2005, Functional visual behaviour: A therapist's guide to evaluation and treatment options, 2nd edn., AOTA Publication, Bethesda, MD.

Hewes, J., 2006, Let the children play: Nature's answer to early learning, Early Childhood Learning Knowledge Centre, Vancouver.

Hewitt, K., 2001, 'Blocks as a tool for learning: A historical and contemporary perspective', Young Children 56(1), 6-14. https://doi.org/10.1097/00001163-200114010-00002

Kalliala, M., 2005, Play culture in a changing world, McGraw-Hill Education, Maidenhead, Berkshire.

Kellman, P.J. \& Arterberry, M., 2006, 'Infant visual perception', in D. Kuhn \& R.S. Siegler (eds.), Handbook of child psychology, cognition perception and language, 6th edn., vol. 2, pp.109-160, John Wiley \& Sons, New Jersey.

Mayer, D., Sodian, B., Koerber, S. \& Schwippert, K., 2014, 'Scientific reasoning in elementary school children: Assessment and relations with cognitive abilities', Learning and Instruction 29, 43-55. https://doi.org/10.1016/j.learninstruc.2013.07.005

Mielonen, A. \& Paterson, W., 2009, 'Developing literacy through play', Journal of Inquiry and Action in Education 3(1), 2.

Mooney, C.G., 2000, Theories of childhood: An introduction to Dewey, Montessori, Erikson, Piaget, Red Leaf Press, St Paul, MN.

Nath, S. \& Szücs, D., 2014, 'Construction play and cognitive skills associated with the development of mathematical abilities in 7-year-old children', Learning and Instruction 32, 73-80. https://doi.org/10.1016/j.learninstruc.2014.01.006

Piaget, J., 1953, The origin of intelligence in the child, Routledge, Kegan Paul, London.

Piaget, J., 1962, Play, dreams and imitation in children, W.W. Norton \& Co, New York.

Piaget, J., 1964, 'Part I: Cognitive development in children: Piaget development and learning', Journal of Research in Science Teaching 2(3), 176-186. https://doi. org/10.1002/tea.3660020306 
Pratt, C., 1948, I learn from children, Perennial Library/HarperCollins, New York.

Ogunyemi, F.T. \& Ragpot, L., 2015, 'Work and play in early childhood education: Views from Nigeria and South Africa', South African Journal of Childhood Education 5(3), Art. \#344, 7 pages. https://doi.org/10.4102/sajce.v5i3.344

Sattler, J. \& Evans, C., 2002, 'Visual impairments', in J.M. Sattler (ed.), Assessment of children. Behavioural and clinical applications, 4th edn., pp. 367-376, Jerome, San Diego, CA.

Scheiman, M. \& Gallaway, M., 2006, 'Optometric assessment: Visual information processing problems', in M. Schleiman \& M. Rouse (eds.), Optometric management of learning related vision problems, 2nd edn., pp. 369-406, Mosby-Elsevier, St Louis, MI.

Scheiman, M. \& Rouse, M., 2006, Optometric management of learning-related vision problems, 2nd edn., Moseby-Elsevier, St Louis, MI.

Schneck, C.M., 2005, 'Visual perception', in J. Case-Smith (ed.), Occupational therapy in children, 5th edn., pp. 412-446, Mosby-Elsevier, St Louis, MI.
Tsai, C.-L., Wilson, P.H. \& Wu, S.K., 2008, 'Role of visual-perceptual skills (non-motor) in children with developmental coordination disorder', Human Movement Science 27(4), 649-664. https://doi.org/10.1016/j.humov.2007.10.002

Tsao, Y.-L., 2008, 'Using guided play to enhance children's conversation, creativity and competence in literacy', Education 128(3), 515.

Vygotsky, L.S., 1978, Mind in society, Harvard University Press, Cambridge, MA.

Wardle, F., 2008, 'Play as curriculum', in Early childhood news: The professional resource for teachers and parents, online resource for Teachers and Parents of children, from infants to age 8 years, viewed 27 May, 2019, from http://www. earlychildhoodnews.com/earlychildhood/article_view.aspx?ArticleID=127.

Whitebread, D. \& O'Sullivan, L., 2012, 'Preschool children's social pretend play: Supporting the development of meta-communication, metacognition and selfregulation', International Journal of Play 1(2), 197-213. https://doi.org/10.1080/ 21594937.2012.693384 